\title{
Abnormal Cervical Vestibular-Evoked Myogenic Potentials Predict Evolution of Isolated Recurrent Vertigo into Meniere's Disease
}

\author{
Sun-Uk Lee ${ }^{1}$, Hyo-Jung Kim ${ }^{2}$, Jeong-Yoon Choi ${ }^{1}$, Ja-Won Koo ${ }^{3}$ and Ji-Soo Kim ${ }^{1 *}$ \\ 'Department of Neurology, Seoul National University College of Medicine, Seoul National University Bundang Hospital, \\ Seongnam, South Korea, ${ }^{2}$ Research Administration Team, Seoul National University Bundang Hospital, Seongnam, \\ South Korea, ${ }^{3}$ Department of Otolaryngology, Seoul National University College of Medicine, Seoul National University \\ Bundang Hospital, Seongnam, South Korea
}

OPEN ACCESS

Edited by: Jose Antonio Lopez-Escamez, Hospital Universitario Virgen de las Nieves, Spain

Reviewed by: Eduardo Martin-Sanz, Hospital de Getafe, Spain Raquel Manrique-Huarte, University of Navarra Clinic, Spain

${ }^{*}$ Correspondence: Ji-Soo Kim jisookim@snu.ac.kr

Specialty section: This article was submitted to Neuro-Otology, a section of the journa Frontiers in Neurology

Received: 15 July 2017 Accepted: 21 August 2017 Published: 04 September 2017

Citation:

Lee S-U, Kim H-J, Choi J-Y, Koo J-W and Kim J-S (2017) Abnormal Cervical Vestibular-Evoked Myogenic

Potentials Predict Evolution of Isolated Recurrent Vertigo into Meniere's Disease.

Front. Neurol. 8:463. doi: 10.3389/fneur.2017.00463
Introduction: Vestibular-evoked myogenic potentials (VEMPs) can be abnormal in patients with idiopathic recurrent spontaneous vertigo. We aimed to determine whether abnormal cervical vestibular-evoked myogenic potentials (cVEMPs) can predict evolution of isolated recurrent vertigo into Meniere's disease (MD).

Methods: We had followed up 146 patients with isolated recurrent vertigo and an evaluation of cVEMPs for 0-142 months [median $=6$, interquartile range $(I Q R)=0-29$ ] at the Dizziness Clinic of Seoul National University Bundang Hospital from June 2003 to May 2014. We defined the variables associated with a progression into MD and calculated cumulative progression rates.

Results: Among the 94 patients with recurrent vertigo and abnormal cVEMPs, 18 (18/94, $19 \%)$ showed an evolution into MD while only 2 of the 50 (4\%) patients with normal cVEMPs evolved into MD during the follow-up $(p=0.01)$. The interval between onset of vertigo and development of cochlear symptoms ranged from 1 month to 13.6 years (median $=3$ years, IQR $=0.5-4.5$ years). Overall, pure tone audiometry (PTA) threshold at $0.25 \mathrm{kHz}$ [hazard ratio $(\mathrm{HR})=1.1,95 \%$ confidence interval $(\mathrm{Cl})=1.0-1.2$ ] and abnormalities of cVEMPs ( $\mathrm{HR}=5.6,95 \% \mathrm{Cl}=1.3-25.5)$ were found to be significantly associated with a later conversion into MD. The cumulative progression rate was $12 \%$ $(95 \% \mathrm{Cl}=5-18)$ at 1 year, $18 \%(8-26)$ at 2 years, and $22 \%(11-32)$ at 3 years.

Conclusion: Abnormal cVEMPs may be an indicator for evolution of isolated recurrent vertigo into MD. Patients with isolated recurrent vertigo may be better managed conforming to MD when cVEMPs are abnormal.

Keywords: Meniere's disease, vertigo, nystagmus, hearing loss, tinnitus, vestibular-evoked myogenic potentials

\section{INTRODUCTION}

Meniere's disease (MD) is characterized by recurrent spontaneous vertigo and fluctuating aural symptoms including tinnitus, ear fullness, and hearing loss (1). Current criteria require both vestibular and cochlear manifestations to diagnose MD (1). However, the initial developments of vestibular and cochlear symptoms may be separated in time in patients with MD (2). Thus, the vestibular symptoms may precede cochlear findings or vice versa. Indeed, about $20 \%$ of patients with recurrent 
vertigo eventually progress to typical MD (3). Previous diagnostic criteria for MD also included sub-categories on these conditions, so-called "vestibular or cochlear MD," to embrace these patients $(1,2,4)$. However, diagnosis of isolated recurrent vertigo remains a challenge since it may occur in various underlying disorders or may evolve into other disorders causing recurrent vertigo. Thus, it would be important to predict evolution of isolated recurrent vertigo into more severe form of disorders causing recurrent vertigo.

Introduction of vestibular-evoked myogenic potentials (VEMPs) has enabled us to evaluate the function of the otolithic organs, the saccule and utricle, more easily. Cervical VEMPs (cVEMPs) in response to air-conducted sounds are known to reflect the uncrossed inhibitory potentials originating from the saccule, while ocular VEMPs (oVEMPs) induced by boneconducted vibration reflect the crossed excitatory potentials originating primarily from the utricle.

Given that the endolymphatic hydrops (EH) mostly starts from the cochlea, and then involves the saccule, which is the vestibular organ closest to the cochlea (5), VEMPs, especially the cVEMPs reflecting the function of the saccule, may be impaired in patients with MD manifesting with isolated recurrent vertigo. The aim of this study was to determine that abnormal cVEMPs and oVEMPs are indeed a predictor for evolution into MD in patients with isolated recurrent vertigo.

\section{MATERIALS AND METHODS}

\section{Subjects}

We retrospectively recruited 303 patients who presented isolated recurrent spontaneous vertigo lasting $20 \mathrm{~min}$ to $24 \mathrm{~h}$ of unknown causes and had an evaluation of cVEMPs at the Dizziness Clinic of Seoul National University Bundang Hospital from June 2003 to May 2014 (1). oVEMPs were performed in 102 of them. We only included the patients who (1) had more than two attacks of spontaneous rotational vertigo that did not occur during head movements or positional changes, (2) denied migrainous headaches or auditory symptoms during or between the attacks, (3) showed no focal neurologic symptoms or signs, and (4) had no other disorders that may explain the recurrent vertigo. We further excluded those with caloric paresis in either ear (canal paresis $>25 \%$ or reduced responses in both ears with sum of slow phase velocity of the nystagmus $<20 \%$ ), abnormal head-impulse tests (either during bedside or video head-impulse tests, $n=116$ ), head-shaking nystagmus (horizontal peak slow phase velocity of nystagmus $>2.9^{\circ} / \mathrm{s}$ or perverted nystagmus, $n=35$ ), and air-bone gap on PTA $(n=6)$. Finally, we included 146 patients with isolated idiopathic recurrent vertigo and evaluation of cervical and/or ocular VEMPs (Figure 1). Cervical and/or ocular VEMPs were conducted within 2 months of the inclusion in most patients [117/146, $80 \%$, median $=22$ days, interquartile range $(\mathrm{IQR})=9-42$ days $]$.

For every patient, a detailed medical history was taken along with a series of vestibular and audiometric tests that included video-oculography, bithermal caloric tests, bedside or video head-impulse tests, cervical and/or ocular VEMPs, and audiometry (6). Evolution into MD was decided when the patients began to meet the diagnostic criteria for probable or definite MD (1). The affected ear was decided with the side of auditory symptoms including hearing loss, tinnitus, and ear fullness. Brain MRIs were obtained in 98 patients $(98 / 146,67 \%)$, which did not show any lesion responsible for the recurrent vertigo.

\section{Cervical and Ocular VEMPs}

Cervical vestibular-evoked myogenic potentials were recorded with the subject supine on a bed with the head raised approximately $30^{\circ}$ from the horizontal and rotated contralaterally in order to activate the sternocleidomastoid (SCM) muscles. The surface EMG activity was measured from an active electrode placed over the belly of the contracted SCM after subtracting activity from a reference electrode located on medial clavicle. A ground electrode was attached to the forehead. cVEMPs were recorded using a Nicolet Viking Select unit (Nicolet-Biomedical, Madison, WI, USA). A short burst of alternating tone (110 dB $\mathrm{nHL}, 123.5 \mathrm{~dB} \mathrm{SPL}, 500 \mathrm{~Hz}$, rise time $=2 \mathrm{~ms}$, plateau $=3 \mathrm{~ms}$, fall time $=2 \mathrm{~ms}$ ) was applied at $2.1 \mathrm{~Hz}$ monaurally via a headphone. The analysis time for each stimulus was $50 \mathrm{~ms}$ and responses elicited by up to 80 stimuli were averaged for each test. The signal was bandpass filtered at $30-1,500 \mathrm{~Hz}$, and the mean values of at least two trials were obtained from each ear for all participants. During each recording, the amplified EMG activities of the SCM were also monitored and digitized at $1 \mathrm{kHz}$ using an analog-todigital converter (NI PCI-4461, National Instruments, Austin, TX, USA). The LabVIEW program (National Instruments) was used to analyze the peak to peak amplitudes and calculate the mean tonic activation during the recording. The absolute cVEMP amplitude was then normalized against the mean tonic activation of the SCM during the recording. To compare the normalized $\mathrm{p} 1-\mathrm{n} 1$ amplitudes of the cVEMPs between the sides, the interaural difference ratio of the normalized amplitudes ( $\left.\mathrm{IAD}_{\text {amp }}, \%\right)$ was also calculated as $[(\mathrm{Ar}-\mathrm{Al}) /(\mathrm{Ar}+\mathrm{Al}) \times 100]$, where $\mathrm{Ar}$ and $\mathrm{Al}$ are the normalized $\mathrm{p} 1-\mathrm{n} 1$ amplitude on the right and left sides, respectively. Both the $\mathrm{p} 1$ and $\mathrm{n} 1$ peak latencies were also calculated. Normative data of cVEMPs were obtained from 28 age-matched healthy subjects ( 13 men, mean age $=52.3 \pm 10$, $p=0.073$ ) with no history of auditory or vestibular disorders (7).

Ocular vestibular-evoked myogenic potentials were recorded with the subject sitting while looking at a target that was displaced more than $2 \mathrm{~m}$ from the eyes and at an angle of more than $20^{\circ}$ upward. EMG activities were recorded using surface electrodes. An active electrode was placed $1 \mathrm{~cm}$ below the center of the lower eyelid and the reference electrode was attached to the cheek $2 \mathrm{~cm}$ below the active electrode. The ground electrode was located on the forehead at Fpz. oVEMPs were elicited by tapping the hairline at AFz using an electric reflex hammer (VIASYS Healthcare, CA, USA). oVEMPs were recorded using a Nicolet Viking Select unit (NicoletBiomedical). Bilateral responses were simultaneously obtained whenever tapping stimuli were applied. oVEMPs in response up to 60 stimuli were averaged for each test, and the average latency of the initial negative peak $(\mathrm{n} 1)$ and the $\mathrm{n} 1-\mathrm{p} 1$ amplitude were analyzed. The interaural difference ratio of the amplitude of the oVEMPs was calculated as $\operatorname{IAD}_{\text {amp }}(\%)$ $[(\mathrm{Ar}-\mathrm{Al}) /(\mathrm{Ar}+\mathrm{Al}) \times 100]$, where $\mathrm{Ar}$ and $\mathrm{Al}$ are the $\mathrm{n} 1-\mathrm{p} 1$ amplitude on the right and left sides, respectively (7). 


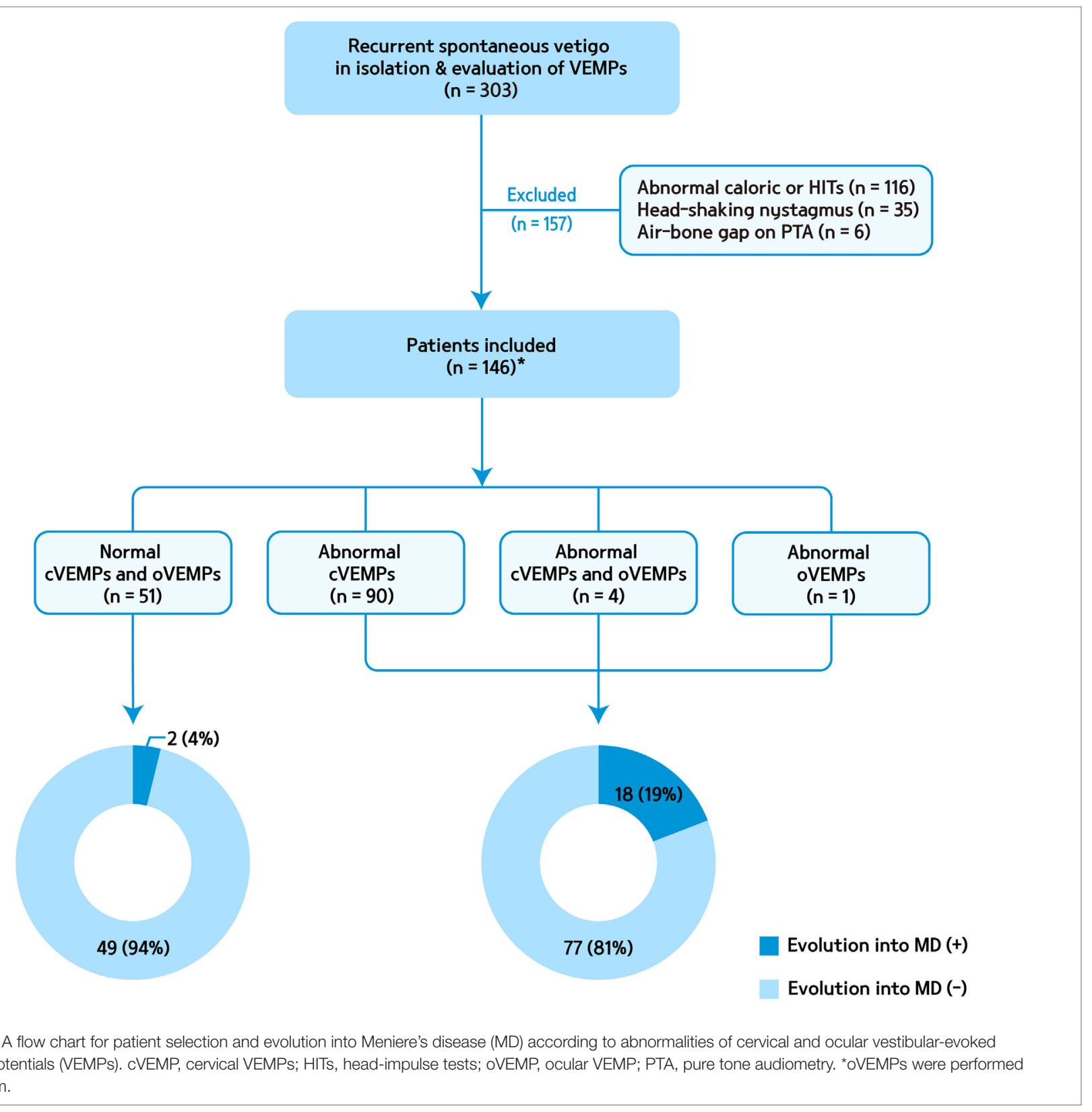

\section{Pure Tone Audiometry}

All patients underwent PTA using air- and bone-conducted signals in an acoustic booth. The hearing threshold was measured at $0.25,0.5,1,2,3,4$, and $8 \mathrm{kHz}$. The audiometric evidence for definite $\mathrm{MD}$ was defined as low- to medium-frequency sensorineural hearing loss documented with PTA (1). If multiple audiograms were performed before treatment, and demonstrated fluctuation of hearing threshold, the pure tone threshold was decided by the hearing threshold of higher (i.e., worse) one.

\section{Statistical Analysis}

The Kaplan-Meier product-limit method was used to calculate cumulative progression rates. Differences between the groups were analyzed using the log-rank test. Weighted log-rank tests (Peto-Prentice log-rank test; $\rho=1$ ) (8) was applied to minimize the effects of rare incidence of evolution into MD and different follow-up periods among the patients. Cox proportional hazards models were used for univariate and multivariate prognostic analyses. All variables with a $p$-value $<0.2$ using univariate analysis were included in the multivariate analysis. Then, all variables with a $p$-value $<0.05$ were decided to be significant in the multivariate analysis. All analyses were performed with $\mathrm{R}$ release 4.3.3 software.

This study followed the tenets of the Declaration of Helsinki and obtained an approval from the Institutional Review Board of Seoul National University Bundang Hospital (B-1109/135-106). 


\section{RESULTS}

\section{Evolution of Isolated Recurrent Vertigo into MD}

Table 1 summarizes the clinical findings and results of audiometry and VEMPs in the patients. The mean and median durations of the follow-up were $20(\mathrm{SD}=30)$ and 6 months ( $\mathrm{IQR}=0-29)$.

Of the 146 patients finally included in this study, 20 showed an evolution into MD (14\%, eight with definite and 12 with probable $\mathrm{MD}, 18$ with unilateral and two with bilateral MD) by developing cochlear symptoms later. The initial cochlear symptoms included tinnitus $(n=14)$, ear fullness $(n=9)$, and hearing loss $(n=5)$. The interval between the onset of vertigo and the development of cochlear symptoms ranged from 1 month to 13.6 years ( median $=3$ years, IQR $=0.5-4.5$ years).

In patients with an evolution into $\mathrm{MD}(n=20)$, the median interval from the onset of follow-up to conversion was 7 months (IQR range $=2-33$ ). The cumulative progression rate was $12 \%$ [95\% confidence interval $(\mathrm{CI})=5-18]$ at 1 year, $18 \%(8-26)$ at 2 years, and $22 \%(11-32)$ at 3 years.

\section{Findings of VEMPs in Isolated Recurrent Vertigo}

Cervical vestibular-evoked myogenic potentials were abnormal in $94(94 / 146,65 \%)$ patients, which included absent responses in 20 (10 on the left, 5 on the right, and the remaining 5 on both sides), delayed responses in 16 (8 on the left, 8 on the right, and the remaining 3 on both sides) and asymmetric responses in 65 . Four patients showed both delayed and asymmetric responses and three patients showed absent responses in one ear, and delayed responses in the other ear.

Of the 94 patients with abnormal cVEMPs, 18 (19\%) showed an evolution into MD, while only 2 of the 51 (4\%) patients with normal cVEMPs evolved into MD during the follow-up

TABLE 1 | Clinical and laboratory findings in the patients with and without evolution into MD.

\begin{tabular}{lccc}
\hline & $\begin{array}{c}\text { Evolution into } \\
\text { MD (+) }(\boldsymbol{n}=\mathbf{2 0})\end{array}$ & $\begin{array}{c}\text { Evolution into } \\
\text { MD (-) }(\boldsymbol{n}=\mathbf{1 2 6})\end{array}$ & $\boldsymbol{p \text { -Value }}$ \\
\hline Age & $53 \pm 13$ & $53 \pm 14$ & 0.994 \\
Female sex (\%) & $13 / 20(65)$ & $98 / 126(78)$ & 0.214 \\
Mean follow-up periods & $20 \pm 26$ & $17 \pm 27$ & 0.648 \\
(months) & & & \\
Attack frequency (/year) & $7 \pm 7$ & $8 \pm 21$ & 0.769 \\
Attack duration (h) & $3 \pm 3$ & $4 \pm 3$ & 0.161 \\
cVEMP abnormalities (\%) & $18 / 20(90)$ & $76 / 126(60)$ & 0.011 \\
oVEMP abnormalities (\%) & $1 / 10(10)$ & $4 / 64(6)$ & 0.527 \\
PTA threshold (kHz) & & & \\
0.25 & $16 \pm 14$ & $9 \pm 6$ & 0.047 \\
0.50 & $15 \pm 15$ & $10 \pm 8$ & 0.223 \\
1 & $15 \pm 15$ & $11 \pm 7$ & 0.043 \\
2 & $16 \pm 15$ & $12 \pm 9$ & 0.202 \\
3 & $20 \pm 17$ & $16 \pm 13$ & 0.270 \\
4 & $23 \pm 20$ & $20 \pm 15$ & 0.449 \\
8 & $35 \pm 24$ & $30 \pm 20$ & 0.398 \\
\hline
\end{tabular}

cVEMPs, cervical vestibular-evoked myogenic potentials; MD, Meniere's disease; oVEMPs, ocular VEMPs; PTA, pure tone audiometry.
(Figure 1). Overall, in 20 patients with an evolution into MD, cVEMPs were depressed $(n=12)$, augmented $(n=5)$, normal $(n=2)$, absent $(n=2$, including one with absent responses in one ear, and depressed in the other ear), or delayed ( $n=1$, both delayed and depressed VEMPs in one ear). Among 18 patients with an evolution into unilateral MD, abnormal cVEMP responses were observed during stimulation of the lesioned ear in 16 patients $(16 / 18,89 \%)$, including depressed $(n=8)$, augmented $(n=5)$, absent $(n=2)$, or delayed responses $(n=1)$. cVEMP responses were usually normal during stimulation of the healthy ear $(13 / 18$, $72 \%)$. However, the remaining five patients showed abnormal cVEMPs which included depressed $(n=5)$ or delayed responses ( $n=2$, both delayed and depressed responses). Two patients with bilateral MD showed decreased responses in both ears. Between the patients with and without an evolution into $\mathrm{MD}$, there were no differences in the p13 n23 latencies, normalized amplitude, and $\mathrm{IAD}_{\text {amp }}$ (Table 2).

Among the 74 patients with a testing of oVEMPs, four showed unilateral (two during right ear stimulation, and the other two during left ear stimulation), and one showed bilateral abnormalities. Among the five patients with abnormal oVEMPs, one with bilaterally delayed responses developed unilateral MD during the follow-up while the other four remained free of cochlear symptoms. There were no differences in the $\mathrm{n} 1, \mathrm{p} 1$ latencies, and $\mathrm{IAD}_{\mathrm{amp}}$ between those with and without an evolution into $\mathrm{MD}$ (Table 2).

\section{Relationship between VEMP Abnormalities and Evolution into MD}

In univariate analysis, progression was associated with PTA threshold at 0.25, $0.5 \mathrm{kHz}$, and abnormal cVEMPs (Table 3). In addition, PTA threshold at $0.25 \mathrm{kHz}$ [hazard ratio $(\mathrm{HR})=1.1$, 95\% CI $=1.0-1.2]$ and abnormalities of cVEMPs ( $\mathrm{HR}=5.6,95 \%$ $\mathrm{CI}=1.3-25.5)$ were found to be significantly associated with a later conversion into MD with multivariate analysis (Table 3). Patients with abnormal cVEMPs showed a more frequent evolution into $\mathrm{MD}$ than those with normal cVEMPs ( $p=0.01$, Figure 2$)$.

TABLE 2 | Cervical and ocular VEMPs in the patients.

\begin{tabular}{|c|c|c|c|c|c|}
\hline & & \multicolumn{2}{|c|}{ Evolution into MD (+) } & \multirow{2}{*}{$\begin{array}{c}\text { Evolution into } \\
\text { MD (-) }\end{array}$} & \multirow[t]{2}{*}{$p$-Value } \\
\hline & & $\begin{array}{l}\text { Lesioned } \\
\text { ear }\end{array}$ & $\begin{array}{l}\text { Opposite } \\
\text { ear }\end{array}$ & & \\
\hline \multirow[t]{4}{*}{ cVEMPs } & p13 (ms) & $15.1 \pm 1.3$ & $15.1 \pm 1.4$ & $15.3 \pm 1.5$ & 0.729 \\
\hline & n23 (ms) & $23.8 \pm 2.1$ & $24.1 \pm 1.7$ & $24.2 \pm 2.2$ & 0.778 \\
\hline & $\begin{array}{l}\text { Normalized } \\
\text { amplitude } \\
(\mu \mathrm{V})\end{array}$ & $2.7 \pm 1.9$ & $2.9 \pm 1.3$ & $3.5 \pm 1.9$ & 0.137 \\
\hline & $\mid A D_{a m p}(\%)$ & \multicolumn{2}{|c|}{$32 \pm 27$} & $27 \pm 29$ & 0.430 \\
\hline \multirow[t]{3}{*}{ oVEMPs } & $\mathrm{n} 1$ (ms) & $7.1 \pm 0.9$ & $7.1 \pm 1.0$ & $6.8 \pm 1.2$ & 0.614 \\
\hline & p1 (ms) & $11.8 \pm 1.5$ & $12.3 \pm 2.4$ & $11.4 \pm 1.9$ & 0.401 \\
\hline & $\mid A D_{a m p}(\%)$ & \multicolumn{2}{|c|}{$4.2 \pm 4.0$} & $8.5 \pm 6.7$ & 0.071 \\
\hline
\end{tabular}

VEMPs, vestibular-evoked myogenic potentials; cVEMPs, cervical vestibular-evoked myogenic potentials; $I A D_{\text {amp, }}$ interaural difference of the normalized amplitudes; $M D$, Meniere's disease; oVEMPs, ocular VEMPS. 
TABLE 3 | Univariate and multivariate prognostic analyses for predicting MD conversion.

\begin{tabular}{|c|c|c|c|c|}
\hline \multirow[t]{2}{*}{ Variables } & \multicolumn{2}{|c|}{ Univariate analysis } & \multicolumn{2}{|c|}{ Multivariate analysis } \\
\hline & HR (95\% Cl) & $p$-value & HR (95\% Cl) & $p$-Value \\
\hline Age & $1.00(0.97-1.03)$ & 0.933 & & \\
\hline Female sex & 1.95 (0.78-4.9) & 0.155 & 0.75 (0.28-1.99) & 0.563 \\
\hline $\begin{array}{l}\text { Attack frequency } \\
\text { (/year) }\end{array}$ & 1.00 (0.98-1.03) & 0.753 & 1.00 (0.97-1.03) & 0.920 \\
\hline $\begin{array}{l}\text { Abnormal } \\
\text { cVEMPs }\end{array}$ & $5.59(1.28-24.35)$ & $0.022^{\star}$ & $5.64(1.25-25.50)$ & $0.025^{\star}$ \\
\hline $\begin{array}{l}\text { Abnormal } \\
\text { oVEMPs }\end{array}$ & $1.98(0.24-16.27)$ & 0.523 & & \\
\hline $\begin{array}{l}\text { PTA threshold } \\
\text { at } 0.25 \mathrm{kHz}\end{array}$ & $1.05(1.02-1.08)$ & $0.002^{\star}$ & 1.09 (1.00-1.19) & $0.041^{\star}$ \\
\hline $\begin{array}{l}\text { PTA threshold } \\
\text { at } 0.50 \mathrm{kHz}\end{array}$ & $1.04(1.00-1.07)$ & $0.031^{*}$ & 0.97 (0.89-1.05) & 0.429 \\
\hline $\begin{array}{l}\text { PTA threshold } \\
\text { at } 1 \mathrm{kHz}\end{array}$ & $1.04(1.00-1.07)$ & 0.054 & 0.97 (0.90-1.05) & 0.487 \\
\hline $\begin{array}{l}\text { Timing of } \\
\text { evaluation since } \\
\text { vertigo spell }\end{array}$ & $0.99(0.98-1.00)$ & 0.118 & $0.99(0.98-1.00)$ & 0.177 \\
\hline
\end{tabular}

cVEMPs, cervical vestibular-evoked myogenic potentials; HR, hazard ratio; $\mathrm{Cl}$, confidence interval; oVEMPs, ocular VEMPS; PTA, pure tone audiometry. ${ }^{*} p<0.05$.

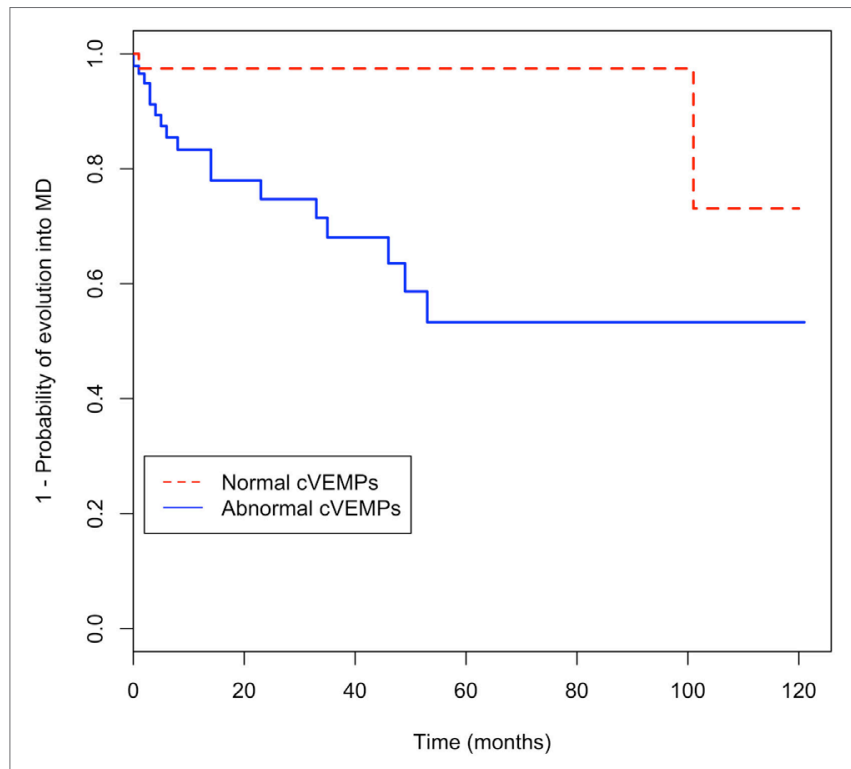

FIGURE 2 | Kaplan-Meier curve for evolution of recurrent vertigo into Meniere's disease (MD) according to abnormalities of cervical vestibularevoked myogenic potentials (cVEMPs).

\section{DISCUSSION}

Our study showed that the PTA threshold at $0.25 \mathrm{kHz}$ and abnormal cVEMPs are significantly associated with a later conversion into MD in patients with recurrent spontaneous vertigo in isolation.

Previously, Slater et al. introduced a group of patients who presents recurrent spells of spontaneous vertigo without any auditory symptoms (9). The term "benign recurrent vertigo (BRV)" was coined to describe this disorder that shares common features with vestibular migraine or MD. Indeed, a genetic link has been raised between BRV and MD with familial studies $(10,11)$. Besides, one-fourth of the relatives of the patients with MD experience spontaneous episodes of vertigo without auditory symptoms (10). Indeed, the term vestibular MD has been adopted in the earlier diagnostic criteria for MD to embrace those patients who develop auditory symptoms later (4). However, existence of this variance was questioned later since patients with vestibular MD showed no clear evidence of $\mathrm{EH}$ involved in the disease process. Furthermore, vestibular migraine can be an alternative explanation for the vertigo episodes or a comorbid condition in those patients (12). As the relationship between BRV and vestibular MD has not been clearly elucidated (13), we aimed to determine the role VEMP abnormality as a biomarker for predicting an evolution of isolated recurrent vertigo into MD. Our hypothesis was that associated otolithic dysfunction is an indicator for further progression of isolated recurrent vertigo into MD. Indeed, a combination of cVEMPs and distortion product otoacoustic emissions (OAEs) permits early diagnosis of MD by showing improvements after glycerol administration (14). Our study also implicates that electrophysiologic changes can precede the clinical symptoms and signs of MD. Indeed, VEMPs may predict whether vestibular symptoms will occur to meet the diagnostic criteria of MD in patients with hearing loss (15). Results of VEMPs also correlate well with histopathologic changes of the saccule (15).

Although cVEMPs had a role in predicting evolution of BRV into MD, oVEMPs did not. In other words, the results of cervical and ocular VEMPs were mostly dissociated in our patients with $\mathrm{BRV}$ that had evolved into MD. The EH is known to involve the vestibular organs in an orderly manner, mostly starting from the cochlear apex and then to saccule, utricle, and ampullae (16). Indeed, the $\mathrm{EH}$ prevails in the cochlea, followed by the saccule that is the vestibular organ closest to the cochlea (5). Due to this adjacency, the cochlear and saccular cells appear to be similarly affected by mechanical bulging of $\mathrm{EH}$ from the earliest stage. Histopathologic studies of the temporal bones of MD patients also support this idea; similar dilation of the cochlear duct and saccule is observed, whereas dilation of the utricle and canals is less frequent (5). Otherwise, the resistance to volume increment of an endolymph-filled closed system would be different according to its geometric configuration and distensibility of the membrane of each vestibular structure (17). The walls of the superior labyrinth (utricle and semicircular canals) are thicker than those of the inferior labyrinth (saccule and cochlear), which could explain their relative resistance to mechanical distortion $(18,19)$. Indeed, a mathematical model showed that the SCCs are most resistant to hydropic expansion while the saccule is most vulnerable (20).

Our patients with an evolution into MD were associated with low-tone hearing impairment on PTA. We may expect that the results of PTA and cVEMPs are correlated since mechanical compression by EH may affect the saccule and cochlea similarly. Indeed, the $\mathrm{IAD}_{\mathrm{amp}}$ ratio of cVEMPs correlates with the clinical staging of MD which is determined by the hearing level on PTA (21). Since EH starts from the cochlear apex that responds to low-frequency sound stimuli, low-tone sensitivity may be 
affected initially by $\mathrm{EH}$ (22). Although lower tone hearing impairments are associated with progression into MD, absence of cutoff value limits their application to an individual patient. Given the decreased amplitude of OAE even in the unaffected ear of MD patients (23) and its correlation with the stages of MD (24), OAE may also help early diagnosis of MD. However, OAE is limited by its high false-positive rate since the results are largely affected by pathologies involving the external or middle ear (25).

The results of VEMPs in our patients were variable to show absent, depressed, normal, or augmented responses. Indeed, asymmetry of cervical or ocular VEMPs does not necessarily indicate the affected side, especially during the earliest stage of MD $(26,27)$. This variability may confuse interpretation of VEMP findings in MD (15, 21, 27-29). We believe that the histopathological status of the saccule may determine the VEMP responses (15): If the sensory epithelium in the saccular macula is totally degenerated, the VEMP responses may be absent. Likewise, the dilated saccule with intact saccular macula may delay VEMPs. The dilated saccule with atrophic saccular macula would show depressed VEMPs. Otherwise, the VEMPs may be augmented if the saccular hydrops displaces the extended footplate attachment, thereby making the saccular macula more sensitive to loud sounds to augment VEMPs (30).

Abnormal cVEMPs may also occur in patients with vestibular migraine $(31,32)$. Since vestibular migraine is also diagnosed in nearly $20 \%$ of patients with MD (2) and the life time prevalence of migraine is increased up to $56 \%$ in patients with MD (33), the abnormal cVEMPs observed in our patients may be ascribed to comorbid vestibular migraine. However, we excluded the patients who met the diagnostic criteria of vestibular migraine, and none of our patients developed vestibular migraine during the followup. Otherwise, abnormal cVEMPs, especially delayed responses, may be observed in central lesions. However, none of our patients showed any focal neurologic deficits on examination, or lesions on brain imaging. In this study, we included only the patients with isolated VEMP abnormalities. This purification of patients may have influenced the results. However, the objective of this study was to determine the role of isolated cVEMP abnormality

\section{REFERENCES}

1. Lopez-Escamez JA, Carey J, Chung W-H, Goebel JA, Magnusson M, Mandalà M, et al. Diagnostic criteria for Menière's disease. J Vestib Res (2015) 25:1-7. doi:10.3233/VES-150549

2. Frejo L, Martin-Sanz E, Teggi R, Trinidad G, Soto-Varela A, Santos-Perez S, et al. Extended phenotype and clinical subgroups in unilateral Meniere disease: a cross-sectional study with cluster analysis. Clin Otolaryngol (2017). doi:10.1111/coa. 12844

3. Rassekh CH, Harker LA. The prevalence of migraine in Meniere's disease. Laryngoscope (1992) 102:135-8. doi:10.1288/00005537-199202000-00006

4. Committee on Hearing and Equilibrium. Report of Subcommittee on Equilibrium and its Measurement. Meniere's disease: criteria for diagnosis and evaluation of therapy for reporting. Trans Am Acad Ophthalmol Otolaryngol (1972) 76(6):1462-4

5. Okuno T, Sando I. Localization, frequency, and severity of endolymphatic hydrops and the pathology of the labyrinthine membrane in Meniere's disease. Ann Otol Rhinol Laryngol (1987) 96(4):438-45. doi:10.1177/ 000348948709600418 in predicting future evolution into MD in patients with idiopathic recurrent vertigo.

Of interest, five patients with an evolution into unilateral MD showed abnormal cVEMPs during stimulation of either ear. We suspect that the abnormal cVEMPs in the contralateral ear may reflect asymptomatic EH. Indeed, 15-27\% of unilateral MD patients have bilateral VEMP changes $(22,29)$. In addition, recent advances in electocochleography (34) and intratympanic gadolinium-enhanced MRIs (35) have allowed detection of asymptomatic $\mathrm{EH}$, and predict a progression from unilateral to bilateral MD. The incidence of bilateral diseases ranges from 9 to $50 \%(36-38)$. This variability may be ascribed to various diagnostic criteria for bilateral MD and different follow-up periods among the literatures. In this regard, histopathologic studies have found more consistent portion of bilaterality at $25-30 \%$ (39-41). Our results indicate that electrophysiologic changes may precede clinical symptoms of MD and abnormalities of cVEMPs are a predictor for evolution of isolated recurrent vertigo into $M D$.

\section{ETHICS STATEMENT}

All experiments followed the tenets of the Declaration of Helsinki and this study was approved by Institutional Review Board of Seoul National University Bundang Hospital (B-1109/135-106).

\section{AUTHOR CONTRIBUTIONS}

S-UL wrote the manuscript, and analyzed and interpreted the data. H-JK, J-YC, and J-WK analyzed and interpreted the data, and revised the manuscript. J-SK designed and conceptualized the study, interpreted the data, and revised the manuscript.

\section{FUNDING}

This research was supported by Basic Science Research Program through the National Research Foundation of Korea (NRF) funded by the Ministry of Education, Science and Technology (NRF-2016R1D1A1B04935568).

6. Huh YE, Kim JS. Bedside evaluation of dizzy patients. J Clin Neurol (2013) 9(4):203-13. doi:10.3988/jcn.2013.9.4.203

7. Kim HJ, Lee JH, Kim JS. Ocular vestibular evoked myogenic potentials to head tap and cervical vestibular evoked myogenic potentials to air-conducted sounds in isolated internuclear ophthalmoplegia. Clin Neurophysiol (2014) 125:1042-7. doi:10.1016/j.clinph.2013.10.013

8. Fleming TR, Harrington DP. Counting Processes and Survival Analysis. Hoboken, NJ: John Wiley \& Sons (2011).

9. Slater R. Benign recurrent vertigo. J Neurol Neurosurg Psychiatry (1979) 42(4):363-7. doi:10.1136/jnnp.42.4.363

10. Cha YH, Kane MJ, Baloh RW. Familial clustering of migraine, episodic vertigo, and Ménière’s disease. Otol Neurotol (2008) 29(1):93-6. doi:10.1097/ mao.0b013e31815c2abb

11. Oh AK, Lee H, Jen JC, Corona S, Jacobson KM, Baloh RW. Familial benign recurrent vertigo. Am JMed Genet (2001) 100(4):287-91. doi:10.1002/ ajmg.1294

12. Cha Y, Brodsky J, Ishiyama G, Sabatti C, Baloh R. The relevance of migraine in patients with Meniere's disease. Acta Otolaryngol (2007) 127(12):1241-5. doi:10.1080/00016480701242469 
13. Dornhoffer JL, Arenberg IK. Diagnosis of vestibular Meniere's disease with electrocochleography. Am J Otol (1993) 14(2):161-4.

14. Magliulo G, Cianfrone G, Cuiuli G, Gagliardi M, D’amico R. Vestibular evoked myogenic potentials and distortion-product otoacoustic emissions combined with glycerol testing in endolymphatic hydrops: their value in early diagnosis. Ann Otol Rhinol Laryngol (2004) 113(12):1000-5. doi:10.1177/ 000348940411301211

15. Young YH, Huang TW, Cheng PW. Vestibular evoked myogenic potentials in delayed endolymphatic hydrops. Laryngoscope (2002) 112(9):1623-6. doi:10.1097/00005537-200203000-00019

16. Pender D. Endolymphatic hydrops and Ménière's disease: a lesion metaanalysis.J LaryngolOtol(2014) 128(10):859-65. doi:10.1017/S0022215114001972

17. Lee SU, Kim HJ, Koo JW, Kim JS. Comparison of caloric and head-impulse tests during the attacks of Meniere's disease. Laryngoscope (2016) 127:702-8. doi:10.1002/lary.26103

18. Pietrantoni L, Iurato S. Some initial electron-microscope investigations of a case of Meniere's syndrome. Acta Otolaryngol (1960) 52:15-26. doi:10.3109/ 00016486009123121

19. Rizvi SS. Investigations into the cause of canal paresis in Meniere's disease. Laryngoscope (1986) 96(11):1258-71. doi:10.1002/lary.1986.96.11.1258

20. Pender DJ. Membrane stress in the human labyrinth and Meniere disease: a model analysis. Int Arch Otorhinolaryngol (2015) 19:336-42. doi:10.1055/ s-0035-1549157

21. Young YH, Huang TW, Cheng PW. Assessing the stage of Meniere's disease using vestibular evoked myogenic potentials. Arch Otolaryngol Head Neck Surg (2003) 129(8):815-8. doi:10.1001/archotol.129.8.815

22. de Waele C, Huy PTB, Diard J-P, Freyss G, Vidal P-P. Saccular dysfunction in Meniere's disease. Am J Otol (1999) 20(2):223-32.

23. de Kleine E, Mateijsen DJ, Wit HP, Albers FW. Evoked otoacoustic emissions in patients with Ménière's disease. Otol Neurotol (2002) 23(4):510-6. doi:10.1097/00129492-200207000-00020

24. Perez N, Espinosa J, Fernandez S, Garcia-Tapia R. Use of distortion-product otoacoustic emissions for auditory evaluation in Meniere's disease. Eur Arch Otorhinolaryngol (1997) 254(7):329-42. doi:10.1007/BF02630725

25. de Sousa LCA, de Toledo Piza MR, da Costa SS. Diagnosis of Meniere’s disease: routine and extended tests. Otolaryngol Clin North Am (2002) 35(3):547-64. doi:10.1016/S0030-6665(02)00029-4

26. Rauch SD, Silveira MB, Zhou G, Kujawa SG, Wall C III, Guinan JJ, et al. Vestibular evoked myogenic potentials versus vestibular test battery in patients with Meniere's disease. Otol Neurotol (2004) 25(6):981-6. doi:10.1097/00129492-200405000-00022

27. Manzari L, Tedesco A-R, Burgess A, Curthoys I. Ocular and cervical vestibularevoked myogenic potentials to bone conducted vibration in Ménière's disease during quiescence vs during acute attacks. Clin Neurophysiol (2010) 121(7):1092-101. doi:10.1016/j.clinph.2010.02.003

28. Young YH, Wu CC, Wu CH. Augmentation of vestibular evoked myogenic potentials: an indication for distended saccular hydrops. Laryngoscope (2002) 112(3):509-12. doi:10.1097/00005537-200203000-00019

29. Lin MY, Timmer FC, Oriel BS, Zhou G, Guinan JJ, Kujawa SG, et al. Vestibular evoked myogenic potentials (VEMP) can detect asymptomatic saccular hydrops. Laryngoscope (2006) 116(6):987-92. doi:10.1097/01.mlg. 0000216815.75512 .03
30. Colebatch J, Halmagyi G. Vestibular evoked potentials in human neck muscles before and after unilateral vestibular deafferentation. Neurology (1992) 42(8):1635-6. doi:10.1212/WNL.42.8.1635

31. Murofushi T, Ozeki H, Inoue A, Sakata A. Does migraine-associated vertigo share a common pathophysiology with Meniere's disease? Study with vestibular-evoked myogenic potential. Cephalalgia (2009) 29(12):1259-66. doi:10.1111/j.1468-2982.2009.01860.x

32. Boldingh MI, Ljøstad U, Mygland Å, Monstad P. Vestibular sensitivity in vestibular migraine: VEMPs and motion sickness susceptibility. Cephalalgia (2011) 31(11):1211-9. doi:10.1177/0333102411409074

33. Radtke A, Lempert T, Gresty M, Brookes G, Bronstein A, Neuhauser H. Migraine and Ménière's disease: is there a link? Neurology (2002) 59(11): 1700-4. doi:10.1212/01.WNL.0000036903.22461.39

34. Iseli C, Gibson W. A comparison of three methods of using transtympanic electrocochleography for the diagnosis of Meniere's disease: click summating potential measurements, tone burst summating potential amplitude measurements, and biasing of the summating potential using a low frequency tone. Acta Otolaryngol (2010) 130(1):95-101. doi:10.3109/00016480902858899

35. Fukuoka H, Tsukada K, Miyagawa M, Oguchi T, Takumi Y, Sugiura M, et al. Semiquantitative evaluation of endolymphatic hydrops by bilateral intratympanic gadolinium-based contrast agent (GBCA) administration with MRI for Meniere's disease. Acta Otolaryngol (2010) 130(1):10-6. doi:10.3109/00016480902858881

36. Merchant S, Rauch S, Nadol J. Meniere's disease. Eur Arch Otorhinolaryngol (1995) 252(2):63-75.

37. Green JD, Blum DJ, Harner SG. Longitudinal followup of patients with Meniere's disease. Otolaryngol Head Neck Surg (1991) 104(6):783-8. doi:10.1177/019459989110400603

38. Nabi S, Parnes LS. Bilateral Ménière’s disease. Curr Opin Otolaryngol Head Neck Surg (2009) 17(5):356-62. doi:10.1097/MOO.0b013e3283304cb3

39. Tsuji K, Velázquez-Villaseñor L, Rauch SD, Glynn RJ, Wall C, Merchant SN. Temporal bone studies of the human peripheral vestibular system. Meniere's disease. Ann Otol Rhinol Laryngol Suppl (2000) 181:26-31. doi:10.1177/ 00034894001090S505

40. Yazawa Y, Kitahara M. Bilateral endolymphatic hydrops in Meniere’s disease: review of temporal bone autopsies. Ann Otol Rhinol Laryngol (1990) 99(7):524-8. doi:10.1177/000348949009900705

41. Perez R, Chen JM, Nedzelski JM. The status of the contralateral ear in established unilateral Meniere's disease. Laryngoscope (2004) 114(8):1373-6. doi:10.1097/00005537-200408000-00010

Conflict of Interest Statement: S-UL, H-JK, J-YC, and J-WK have no potential conflicts of interest to disclose. J-SK serves as an Associate Editor of Frontiers in Neuro-otology and on the Editorial Boards of Journal of Clinical Neurology, Frontiers in Neuro-ophthalmology, Journal of Neuro-ophthalmology, Journal of Vestibular Research, and Journal of Neurology, and Medicine.

Copyright (C) 2017 Lee, Kim, Choi, Koo and Kim. This is an open-access article distributed under the terms of the Creative Commons Attribution License (CC BY). The use, distribution or reproduction in other forums is permitted, provided the original author(s) or licensor are credited and that the original publication in this journal is cited, in accordance with accepted academic practice. No use, distribution or reproduction is permitted which does not comply with these terms. 